\title{
Cardiac Output Thermodilution Method
}

National Cancer Institute

\section{Source}

National Cancer Institute. Cardiac Output Thermodilution Method. NCI Thesaurus. Code C150870.

A technique for calculating cardiac output using a Swan-Ganz catheter that is inserted into the pulmonary artery through a peripheral vein to measure the change in right ventricular outflow blood temperature after a cold saline solution is injected into the right atrium from a proximal catheter port. 